\title{
Effect of COVID-19 in geriatric individuals and role of a prosthodontist in clinical setup in Indian populations: a literature review
}

\author{
Bappaditya Bhattacharjee, Pinki Gupta, Atul Bhatnagar*, \\ Ankita Singh, Ritu Saneja
}

Department of Prosthodontics, Faculty of Dental Sciences, Banaras Hindu University, Varanasi, Uttar Pradesh, India

Received: 09 July 2020

Revised: 19 August 2020

Accepted: 05 September 2020

*Correspondence:

Dr. Atul Bhatnagar,

E-mail: atuldent@hotmail.com

Copyright: ( ) the author(s), publisher and licensee Medip Academy. This is an open-access article distributed under the terms of the Creative Commons Attribution Non-Commercial License, which permits unrestricted non-commercial use, distribution, and reproduction in any medium, provided the original work is properly cited.

\begin{abstract}
Medical professionals including dentists are one of those high-risk professionals who can easily get affected by COVID-19 due to its highly contagious nature. Evaluating the molecular pathogenesis and the role of immune system in modulating symptoms it can be assumed that susceptibility of COVID-19 to older adults is more. This review aimed to summarize all the information available on electronic databases PubMed, PubMed central, Cochrane database related to the effect of COVID-19 in geriatric individuals and guidelines for a prosthodontist during treatment of geriatric individuals in Indian population during this pandemic period. This review will focus on the characteristic symptoms and signs of COVID-19 in geriatric individuals and how the prosthodontists during treatment of geriatric individuals in Indian populations can better equip themselves to prevent the spread of COVID-19 in a clinical setup.
\end{abstract}

Keywords: COVID-19, Geriatric patients, Prosthodontic guidelines, SARS-CoV-2

\section{INTRODUCTION}

In the present condition COVID-19 is a major threat all over the world. Medical professionals including dentists are one of those high-risk professionals who can easily get affected by this disease due to its highly contagious nature. The first case of novel coronavirus (COVID- 19) was reported back on $12^{\text {th }}$ December 2019 in Wuhan (Hubei province, China). Wu et al conducted a study on a patient admitted to the central hospital of Wuhan on 26 December 2019 while experiencing a severe respiratory syndrome with fever, dizziness, and a cough. They had done metagenomic RNA sequencing of a sample of bronchoalveolar lavage fluid from the patient and identified a new RNA virus strain from the family coronaviridae, which was designated as 'WH-Human 1' coronavirus. ${ }^{1}$ World health organization (WHO) on $11^{\text {th }}$ February 2020 announced a new term 'COVID-19' (coronavirus disease of 2019) for this virus (previously known by "severe acute respiratory syndrome coronavirus 2). Previous researches suggested that bats are the natural hosts for SARS-CoV and that civets are only intermediate hosts. ${ }^{2}$ Many coronaviruses phylogenetically related to SARS-CoV (SARSs-CoVs) were discovered in bats from different provinces in China, as well as European, African and Southeast Asian countries. ${ }^{3-5}$ Human-to-human transmission of SARSCoV-2 occurs mainly through intimate contact and incubation carriers. Family members and those having intimate contact with diseased persons always have a risk of this disease. ${ }^{6}$ SARS-CoV-2 can be transmitted by droplets and contact but not through faeco-oral route. , $^{6}$ There is a high risk of transmission for dental professionals and patients attending dental clinics due to dental problems because of increased aerosol content in any dental setup. A recent report suggested that face-to- 
face communication and consistent exposure to body fluids such as blood and saliva predispose dental care workers at serious risk for COVID-19 infection. ${ }^{8}$ So this review article aims to present the characteristics of the disease COVID-19 in geriatric individuals and to review how this disease modulates the treatment procedures for geriatric patients in prosthodontic setup.

\section{CHARACTERISTICS OF COVID-19}

The word "corona" evolved from a Latin word which means 'crown'. These viruses belong to the Coronaviridae family in the Nidovirales order. ${ }^{9}$ According to the shape they are either spherical or pleomorphic enveloped particles. Various glycoprotein projections are present on this envelope and surround a core consisting of matrix protein. A single strand of positive-sense RNA associated with nucleoprotein forms the matrix protein of these viruses. The envelope glycoproteins are the main culprits for attachment to the host cell and they also carry the main antigenic epitopes, which are recognized by neutralizing antibodies. ${ }^{10}$ Four subtypes of coronavirus family are alpha coronavirus, beta coronavirus, gamma coronavirus, and delta coronavirus. Alpha and beta coronaviruses are mainly responsible for infecting mammals; the other two primarily infect birds. ${ }^{11,12}$ Seven coronaviruses related to human disease had been identified till now. ${ }^{2}$ Upper respiratory tract infections in adults are mainly caused by four human coronaviruses (HCoV 229E, NL63, OC43, and HKU1). The SARS-CoV, MERS-CoV, and SARSCoV-2 are the most severe type that causes lower respiratory tract infections and acute respiratory distress syndrome (ARDS). ${ }^{11,13}$ Current evidence from various literature suggest that SARSCoV-2 infects cells by using the human ACE2 (angiotensin-converting enzyme), a cellular receptor. ${ }^{14,15}$ Incubation period of coronaviruses is 6.4 days (95\% credible interval: 5.6-7.7), ranging from 2.1 to 11.1 days $\left(2.5^{\text {th }}\right.$ to $97.5^{\text {th }}$ percentile $){ }^{16}$ The onset period of COVID-19 symptoms to death ranged from 6 to 41 days with a median of 14 days. ${ }^{17}$ The age of the patient and the status of the patient's immune system are the main determining factors of the onset period of these viruses. ${ }^{18}$ For SARS, it was reported that the average duration of first symptoms to hospital admission was 3.8 days, and admission to death was 17.4 days. ${ }^{19}$ One study also found that people of 70-year old or above had shorter median days (11.5 days) from the first symptom to death than those with ages below 70-year old (20 days), demonstrating that elderly people might have faster disease progression than younger people. Similar results were found in case of SARS also, with mean duration from admission to death was 5.7 days for people aged 8093 years, 9.4 days for those aged 60-79 years and above 12.0 days for those under 60 years of age. ${ }^{20}$ Fever (77.4$98.6 \%)$, cough (59.4-81.8\%), fatigue (38.1-69.6\%), dyspnoea (3.2-55.0\%), myalgia (11.1-34.8\%), sputum production $(28.2-56.5 \%)$, and headache $(6.5-33.9 \%)$ are the common symptoms. ${ }^{21-23}$ Sore throat, rhinorrhoea, chest pain, haemoptysis, conjunctival congestion, diarrhoea, nausea, and vomiting are less common symptoms. ${ }^{21-23}$ As of $31^{\text {st }}$ May 2020 there are 6,300,444 active cases are present all over the world. The number of deaths reached up to 374,527 , and recovered cases are $2,866,061$.

\section{SYMPTOMS OF COVID-19 AND ITS EFFECT ON GERIATRIC INDIVIDUALS}

In the USA, $80 \%$ of deaths have occurred in patients suffering from COVID-19 aging 65 and older. The percentage of severe outcomes is more in patients older than 85 years. Diagnosis and triage of older patients are important to maintain the level of care in hospital setup. As early as possible, advance care plans should be reviewed and discussed. Education of family members of older adults regarding the course of the disease and desired quality of life are also important. ${ }^{24}$

It has been shown that coronavirus utilizes $S$ protein to enter into host cells. In humans, for SARS-1 and 2, this entry occurs via the host cell surface enzyme angiotensinconverting enzyme 2 (ACE2) receptor. ${ }^{25}$ The term immune-senescence is known as gradual age-related changes in the immune system that occur as the age increases. ${ }^{26} \mathrm{~A}$ decrease in the production of $\mathrm{T}$ cells is one of the early changes seen as age increases. Adults have only $10 \%$ of the $\mathrm{T}$ cells that were produced in childhood because of gradual atrophy of the thymus, known as involution. ${ }^{27}$ Around 40 and 50 years of age, number of naïve $\mathrm{T}$ cells become almost $1 \%{ }^{28}$ Similarly, the production of $\mathrm{B}$ lymphocytes also decreases in bone marrow. Lymph nodes are the main reservoirs in the body to combat against any viral infections like SARS-CoV 2. These lymph nodes are the main reservoirs of naïve $\mathrm{T}$ and B lymphocytes. $^{29}$

After activation both $\mathrm{T}$ and B lymphocytes show reduced production rate and as age increases the capability of these cells to combat against viral infections reduces. ${ }^{30}$ Liu et al conducted a study and evaluated 56 patients, among them 18 were elderly patients $(32.14 \%)$, and 38 were young patients $(67.86 \%)$. The median age of the elderly group was 68 years (interquartile range (IQR 65.25-69.75), while the median age of the young and middle age group was 47 years (IQR 35.75-51.25), showing a statistically significant difference between the two groups (Table 1). ${ }^{31}$ Fever, followed by cough and sputum were the most common symptoms in both the groups. The PSI (pulmonary severity index) score of the elderly group was higher than that of the young and middle-aged group $(\mathrm{p}<0.001)$. The proportion of patients with PSI grade IV and V was significantly higher in the elderly group than the other group $(\mathrm{p}<0.05) .{ }^{31}$ Godaert et al conducted a similar study in March 2020, by opening a short-stay geriatric unit for elderly polymorbid patients suspected of COVID-19 infection. In the first week, they received 22 patients, 17 of whom were infected with SARS-CoV-2 (confirmed by RT-PCR). Nine were female and the median age was 86.5 years (range: 68.6-97.1). 
According to this study, fever was the most common symptom (observed at home or during admission). Cough, delirium, dyspnoea, and asthenia were the other most commonly observed signs. ${ }^{32}$ According to a study done by Guan et al in 1099 adults during the outbreak in China (median age 47 years), fever (88.7\%), cough $(67.8 \%)$, asthenia/fatigue $(38.1 \%)$, sputum $(33.7 \%)$ were most common symptoms. Diarrhoea was rare $(3.8 \%) .{ }^{33} \mathrm{~A}$ comparative data of two studies on common symptoms of COVID-19 in elderly individuals (Table 2). ${ }^{31,33}$

Signs of cough, dyspnoea, asthenia, and oxygen therapy were observed more often in this study. ${ }^{33}$ In this study, the study population was older compared to previously mentioned study (median age: 86.5 versus 68.0 years). More than a quarter of patients had suffered from diarrhoea, while delirium was present in more than $60 \%$ of the patients. A fall was the first sign of the infection for more than a quarter of our patients. ${ }^{32}$ Guan et al reported that thrombopenia and lymphopenia have been frequently observed in adult patients with COVID-19, but Godaert et al reported lymphopenia was more frequent than thrombopenia or leukopenia in their study. ${ }^{32,33}$

Evaluating the molecular pathogenesis and the role of the immune system in modulating symptoms it can be assumed that susceptibility of COVID-19 to older adults is more. There are various contributing factors for poor health outcomes and these include the physiologic changes of aging; multiple comorbid conditions such as heart and lung disease, diabetes, and dementia; and associated immunosuppressive disorders. Older adults living in senior living facilities are at the highest risk for this disease because of their burden of chronic illness and the impact of congregate housing. However, for all older adults, prevention should be given more importance than other age groups. ${ }^{30}$

\section{PROSTHODONTIC CONSIDERATIONS FOR GERIATRIC AGE GROUP}

As the age increases edentulism become one of the major problems for individuals due to progressive breakdown of periodontal structures. Similarly wasting diseases of teeth also affect the dentition of geriatric individuals because of continuous interproximal and occlusal wear. Dolan et al stated that a total of $19 \%$ of subjects of 45 years of age or older were edentulous by self-report in the USA, and Medina-Solís et al similarly reported that the prevalence of self-reported edentulism ranged from $2 \%$ in the 35-44 year age group to $26 \%$ in the $65-74$ year age group in Mexico. ${ }^{34,35}$ Muller et al conducted a cross-sectional study among 75-year-olds in Swedish, Danish and Finnish cities and the rate of edentulism were $27 \%, 45 \%$, and $58 \%$ respectively. ${ }^{36}$ Rao et al evaluated the oral health status in 287 institutionalized residents in Mangalore in India and they found that none of the subjects had completely healthy periodontium. ${ }^{37}$ There is also a high amount of variability is seen between geriatric individuals regarding the frequency of dental check-ups.
The motivation of an individual and education regarding dental problems and their outcomes are the main determinants for dental visits of these individuals. Various analyses have been done until now to check the reporting rate of geriatric individuals in different countries. Data from the survey of health, ageing, and retirement in Europe (SHARE) 2006-07 and data from of the health and retirement study (HRS) 2004-06 in the United States for respondents aged 51 years and older showed considerable variation across countries in the overall percentage of respondents reporting dental attendance. $^{38}$

\section{GUIDELINES FOR TREATING GERIATRIC PATIENTS IN PROSTHODONTIC SETUP (INDIAN POPULATIONS)}

In dental practice, maximum procedures generate aerosols, which represent the most important clinical concern within this COVID-19 pandemic situation. The viral aerosol spreading was confirmed by SARS-CoV-2 detection in air samples up to four meters away from general COVID-19 wards, and it has also been reported that the virus can survive on surfaces exposed to infected saliva droplets for at least nine days. ${ }^{39}$ Various tissues of the oral cavity show ACE2 receptor, mainly salivary glands, and epithelial cells of the tongue. ${ }^{40}$ Hence, beyond being a source of infected aerosol spread, oral mucosa is highly susceptible to SARS-CoV-2 infection. Several guidelines have been suggested to SARS CoV- 2 infection control to provide shielded dental practice during this pandemic outbreak. ${ }^{40-42}$ Starting treatment through telecommunication or tele dentistry prior to the dental treatment should be prioritized to evaluate the needs of the patient and also to minimize the risk of infection transmission, asking if the patient has a fever, cough, shortness of breath, or any recent traveling history. ${ }^{43}$ Five most common procedures that cause aerosol production in dental operatory are ultrasonic scalers, air polishing, use of air-water syringes, tooth preparation with air-turbine handpieces, and tooth preparation with air-abrasion. Ultrasonic and sonic scalers produce greatest level of aerosol contamination. ${ }^{44}$

According to various guidelines in course of this outbreak, elective procedures have to be postponed. Urgent care such as acute pain relief or mild swelling must be treated remotely with medicine prescription and close follow-up alongside with telephone or video conference. $^{42}$ If patient presents dental emergency (potentially life-threatening situation) such as an uncontrolled bleeding, or an urgent dental need that requires relieve of severe pain and/or risk of infection, and present signs/symptoms of respiratory infection, this patient should not see in dental office and should referred for emergency care facility where transmission-based Precautions (N95 masks, PPE kits, airborne infection isolation room for example) are available (ADA). ${ }^{43}$ In an edentulous patient in need of replacement of missing teeth with removable or fixed prosthesis. during 
fabrication of removable and fixed prosthesis there are chances of transmission of SARS-CoV-2 via saliva during impression making procedures and in further steps of prosthesis fabrication. ${ }^{41}$ Placement of dental implant is also major risk factor for spread of virus due to production of high amount of aerosol during osteotomy. Classification of different prosthodontic procedures in COVID-19 pandemic has been shown in (Table 3). ${ }^{45}$

However, since there are huge numbers of asymptomatic cases of COVID-19, the dentist should take extra care when seeing the patient and should not assume he/she is COVID-19 free. It is crucial to maintain patient isolation (have only one patient in the waiting room), stick to the infection control protocol: standard procedure of putting on personal protective equipment (PPE), including gown, goggles, N95 mask with face full shield and gloves. ${ }^{42}$ An extensive hand hygiene protocol should be maintained by using 60 to $85 \%$ ethyl acohol. ${ }^{43}$ Radiographic evaluations on dental emergencies could be done by sectional dental panoramic radiography or intraoral radiography with sufficient PPE use by dentists and radiography staff. ${ }^{46}$ Elective procedures should be avoided in geriatric individuals even if they are asymptomatic. For immunocompetent patients with no symptoms or exposure history, dental treatment can be executed under specific conditions. An extensive hand hygiene protocol engaging 60 to $85 \%$ hydro-alcoholic solutions, use of PPE and if possible, 4-handle technique should be used. ${ }^{40,41}$ Treatment guidelines according to the dental council of India (DCI) and Indian dental association (IDA) have been presented in (Table 4). ${ }^{47,48}$

All the equipment should be covered with disposable physical barriers and anti-retraction valves should be installed on handpieces. ${ }^{40,41}$ Effectivity of ultraviolet radiation (UV) against bacteria, fungi, viruses has been confirmed previously by many laboratory studies. Ultraviolet light can be an effective treatment protocol for decontamination of surfaces contaminated by SARS CoV-2 by forming photo dimers in the genome of viruses. ${ }^{49}$ Aerosol generation can be diminished by avoiding the use of ultrasonic scaler, bicarbonate jet, 3way syringe, and with the use of rubber dams and high volume saliva ejectors. ${ }^{39}$ Pre-procedural mouth rinses with $1 \%$ hydrogen peroxide or $0.2 \%$ povidone-iodine are indicated to attenuate potential SARS-CoV-2 carriage. ${ }^{40}$ The clinical environment should be disinfected before and after every dental care, with $70 \%$ isopropyl alcohol or $0.1 \%$ sodium hypochlorite. ${ }^{41}$ The garbage must be discharged into double-layer yellow color medical waste package bags with "gooseneck" ligation. ${ }^{40}$

Table 1: Comparison of symptoms of COVID-19 in elderly and younger age groups.

\begin{tabular}{|llll|}
\hline Variable & Elderly $(\mathbf{n = 1 8})(\boldsymbol{\%})$ & Young and middle-aged $(\mathbf{n}=\mathbf{3 8})$ & P value \\
\hline Age (years) & $68.00(65.2569 .75)$ & $47.00(35.75-51.25)$ & $<0.001$ \\
\hline Smoking history & $8(44.44)$ & $14(36.84)$ & 0.667 \\
\hline Clinical symptoms & & $15(39.47)$ & 0.284 \\
\hline Cough and sputum & $6(33.33)$ & $2(5.26)$ & 0.351 \\
\hline Chest tightness, difficulty breathing & $2(11.11)$ & $30(78.95)$ & 0.008 \\
\hline Fever & $14(77.78)$ & $3(7.89)$ & 0.385 \\
\hline Fatigue & $2(11.11)$ & $2(5.26)$ & 0.786 \\
\hline Nasal congestion, runny nose & $1(5.56)$ & $7(18.42)$ & 0.558 \\
\hline Sick and vomit & $3(16.67)$ & & \\
\hline
\end{tabular}

Table 2: Comparison of two different studies on different symptoms of COVID-19 in elderly individuals.

\begin{tabular}{|llll|}
\hline Characteristics & $\begin{array}{l}\text { Study population by } \\
\text { Guan et al }(\mathbf{n}=\mathbf{1 7})(\boldsymbol{\%})\end{array}$ & $\begin{array}{l}\text { Study population by Liu et } \\
\text { al }(\mathbf{n}=\mathbf{1 8})(\boldsymbol{\%})\end{array}$ & \begin{tabular}{l} 
P value \\
\hline Fever
\end{tabular} $13(76.5)$ \\
\hline Cough & $12(70.6)$ & $6(33.8)$ & 1 \\
\hline Dyspnoea & $11(64.7)$ & $2(11.1)$ & 0.03 \\
\hline Asthenia/fatigue & $10(58.8)$ & $2(11.1)$ & 0.001 \\
\hline
\end{tabular}

Table 3: Classification of different prosthodontic procedures during COVID-19 pandemic period.

\begin{tabular}{|c|c|}
\hline Urgent conditions & Non urgent or elective condition \\
\hline $\begin{array}{l}\text { Removable prosthesis adjustment for radiation or oncologic } \\
\text { patients impeding function }\end{array}$ & Removable prosthesis adjustment or repair \\
\hline \multirow[t]{3}{*}{$\begin{array}{l}\text { Fractured or defective fixed prosthesis causing soft tissue } \\
\text { injury }\end{array}$} & Asymptomatic fractured defective fixed prosthesis \\
\hline & $\begin{array}{l}\text { Replacement of missing tooth either with fixed or } \\
\text { removable prosthesis }\end{array}$ \\
\hline & Dental implant surgery \\
\hline
\end{tabular}


Table 4: Guidelines for dentists during COVID-19 pandemic period according to DCI and IDA.

\section{Guidelines for dentists according to dental council of India (DCI)}

Use of alcohol-based hand rub or use of soap and water for washing hands with standard steps recommended by WHO.

PPE is mandatory and would comprise of the following:

- Goggles/face shield (both to be used, fitting goggles with a soft tissue seal).

- $\quad$ Triple layer surgical mask.

- $\quad$ N95 respirator during routine dental procedures.

- $\quad$ FFP3-Standard mask should be used during treatment of COVID19 positive patients.

- Surgical gloves.

- Disposable coverall/gown with hood /waterproof lining (to be changed daily).

- Coverall/gown outer; maybe improvised but will need to be changed after each patient

- Shoe covers

PPE should be judiciously used and appropriately disposed as per protocol.

PPE protocol of wearing and removal should be followed and clearly designated rooms should be assigned.

Change the surgical mask after every dental procedure after every dental procedure.

All instruments pertaining to dental procedures to be disinfected, cleaned and sterilized as per standard infection control (CDC, 2003)

All instruments should be mandatorily disinfected, cleaned, packaged in colour changing sterilization autoclave pouches and proper storage to be done.

All biomedical waste pertaining to patient care should be carefully disposed as per the bio-medical Waste (Management and Handling) Rules, 1998 amended from time to time through an authorized biomedical disposal agency by the state pollution control Board.
Guidelines for dentists according to Indian dental association (IDA)

Post a sign at the entrance to the dental practice which instructs patients having symptoms of a respiratory infection (e.g., cough, sore throat, fever, sneezing, or shortness of breath) to please reschedule their dental appointment and call their physician.

Reschedule appointments if your patients have travelled outside India in the last two weeks to an area affected by the coronavirus disease.

Take a detailed travel and health history

Incorporate questions about new onset of respiratory symptoms

Take temperature readings, Take the contact details and address of all patients treated.

Install physical barriers (e.g., glass or plastic windows) at reception areas

Use a rubber dam, Use high-speed evacuation, Autoclave hand-pieces

Have patients rinse with a $1 \%$ hydrogen peroxide solution before each appointment.

\section{CONCLUSION}

Current researches showed that the prognosis of COVID19 is worst for patients older than 60 years of age and with underlying diseases (diabetes, hypertension or cardiovascular disease, for example) In this sense, members of the health team must use clinical judgment and take all precautions to prevent transmission. In this unprecedented situation, it is advisable to look for and apply the most recent protocols in dental setups to prevent transmission of the disease.

Funding: No funding sources

Conflict of interest: None declared

Ethical approval: Not required

\section{REFERENCES}

1. Wu F, Zhao S, Yu B, Chen YM, Wang W, Song ZG et al. A new coronavirus associated with human respiratory disease in China. Nature. 2020;579:2659.

2. Li W, Shi Z, Yu M, Ren W, Smith C, Epstein JH et al. Bats are natural reservoirs of SARS-like coronaviruses. Science. 2005;310(5748):676-79.

3. Ren W, Li W, Yu M, Hao P, Zhang Y, Zhou P et al. Full-length genome sequences of two SARS-like coronaviruses in horseshoe bats and genetic variation analysis. J General Virol. 2006;87(11):3355-59.

4. Drexler JF, Gloza-Rausch F, Glende J, Corman VM, Muth D, Goettsche $\mathrm{M}$ et al. Genomic characterization of severe acute respiratory syndrome-related coronavirus in European bats and classification of coronaviruses based on partial RNAdependent RNA polymerase gene sequences. J virol. 2010;84(21):11336-49.

5. Lau SK, Li KS, Huang Y, Shek CT, Tse H, Wang M et al. Ecoepidemiology and complete genome comparison of different strains of severe acute respiratory syndrome-related Rhinolophus bat 
coronavirus in China reveal bats as a reservoir for acute, self-limiting infection that allows recombination events. J virol. 2010;84(6):2808-19.

6. Guo YR, Cao QD, Hong ZS, Tan YY, Chen SD, Jin $\mathrm{HJ}$ et al. The origin, transmission and clinical therapies on coronavirus disease 2019 (COVID-19) outbreak-an update on the status. Mil Med Res. 2020;7(1):11.

7. Han Y, Yang H. The transmission and diagnosis of 2019 novel coronavirus infection disease (COVID19): A Chinese perspective. J med virol. 2020;92(6):639-44.

8. Meng L, Hua F, Bian Z. Coronavirus disease 2019 (COVID-19): emerging and future challenges for dental and oral medicine. J Dental Res. 2020;99(5):481-7.

9. Shereen MA, Khan S, Kazmi A, Bashir N, Siddique R. COVID-19 infection: Origin, transmission, and characteristics of human coronaviruses. J Adv Res. 2020;24:91-8.

10. Desforges M, Coupanec AL, Brison E, MeessenPinard M, Talbot PJ. Neuroinvasive and Neurotropic Human Respiratory Coronaviruses: Potential Neurovirulent Agents in Humans. Infect Dis Nanomed I. 2014;807:75-96.

11. Chen Y, Liu Q, Guo D. Emerging coronaviruses: genome structure, replication, and pathogenesis. J med virol. 2020;92(4):418-23.

12. Wu A, Peng Y, Huang B, Ding X, Wang X, Niu P et al. Genome composition and divergence of the novel coronavirus (2019-nCoV) originating in China. Cell Host Microbe. 2020;27(3):325-8.

13. Paules CI, Marston HD, Fauci AS. Coronavirus infections-more than just the common cold. Jama. 2020;323(8):707-08.

14. Wrapp D, Wang N, Corbett KS, Goldsmith JA, Hsieh CL, Abiona $\mathrm{O}$ et al. Cryo-EM structure of the 2019-nCoV spike in the prefusion conformation. Science. 2020;367(6483):1260-63.

15. Zhou Q, Yan R, Zhang Y, Li Y, Xia L. Structure of dimeric full-length human ACE2 in complex with B0AT1. BioRxiv. 2020;1-16.

16. Feng D, Jia N, Fang LQ, Richardus JH, Han XN, Cao WC et al. Duration of symptom onset to hospital admission and admission to discharge or death in SARS in mainland China: a descriptive study. Trop Medi Int Heal. 2009;14:28-35.

17. Backer JA, Klinkenberg D, Wallinga J. Incubation period of 2019 novel coronavirus (2019-nCoV) infections among travellers from Wuhan, China, 2028 January 2020. Euro Surveill. 2020;25(5):2000062.

18. Wang W, Tang J, Wei F. Updated understanding of the outbreak of 2019 novel coronavirus (2019-nCoV) in Wuhan, China. J med virol. 2020;92(4):441-7.

19. Feng D, Jia N, Fang LQ, Richardus JH, Han XN, Cao WC et al. Duration of symptom onset to hospital admission and admission to discharge or death in SARS in mainland China: a descriptive study. Trop Med Int Heal. 2009;14:28-35.
20. Kan B, Wang M, Jing H, Xu H, Jiang X, Yan M et al. Molecular evolution analysis and geographic investigation of severe acute respiratory syndrome coronavirus-like virus in palm civets at an animal market and on farms. J virol. 2005;79(18):11892900.

21. Chang D, Mo G, Yuan X, Tao Y, Peng X, Wang FS et al. Time kinetics of viral clearance and resolution of symptoms in novel coronavirus infection. Am $\mathrm{j}$ respiratory critical care med. 2020;201(9):1150-52.

22. Ren LL, Wang YM, Wu ZQ, Xiang ZC, Guo L, Xu $\mathrm{T}$ et al. Identification of a novel coronavirus causing severe pneumonia in human: a descriptive study. Chin Med J (Engl). 2020;133(9):1015-24.

23. Huang C, Wang Y, Li X, Ren L, Zhao J, Hu Y et al. Clinical features of patients infected with 2019 novel coronavirus in Wuhan, China. lancet. 2020;395(10223):497-506.

24. Nikolich-Zugich J, Knox KS, Rios CT, Natt B, Bhattacharya D, Fain MJ. SARS-CoV-2 and COVID-19 in older adults: what we may expect regarding pathogenesis, immune responses, and outcomes. GeroScience. 2020;42(2):505-14.

25. De Wit E, Van Doremalen N, Falzarano D, Munster VJ. SARS and MERS: recent insights into emerging coronaviruses. Nature Reviews Microbiol. 2016;14(8):523.

26. Nikolich-Žugich J. The twilight of immunity: emerging concepts in aging of the immune system. Nature immunol. 2018;19(1):10-9.

27. Chinn IK, Blackburn CC, Manley NR, Sempowski GD. Changes in primary lymphoid organs with aging. Semin Immunol. 2012;24(5):309-20.

28. Naylor K, Li G, Vallejo AN, Lee WW, Koetz K, Bryl $\mathrm{E}$ et al. The influence of age on $\mathrm{T}$ cell generation and TCR diversity. J Immunol. 2005;174(11):7446-52.

29. Thompson HL, Smithey MJ, Surh CD, NikolichŽugich J. Functional and homeostatic impact of agerelated changes in lymph node stroma. Frontiers immunol. 2017;8:706.

30. Brien JD, Uhrlaub JL, Hirsch A, Wiley CA, Nikolich-Žugich J. Key role of T cell defects in agerelated vulnerability to West Nile virusT cell defects and age-related vulnerability to WNV. J exp med. 2009;206(12):2735-45.

31. Liu K, Chen Y, Lin R, Han K. Clinical features of COVID-19 in elderly patients: A comparison with young and middle-aged patients. J Infect. 2020;80(6):e14-e18.

32. Godaert L, Proye E, Demoustier-Tampere D, Coulibaly PS, Hequet F, Dramé M. Clinical characteristics of older patients: The experience of a geriatric short-stay unit dedicated to patients with COVID-19 in France. J Infect. 2020;81(1):e93-4

33. Guan WJ, Ni ZY, Hu Y, Liang WH, Ou CQ, He JX et al. Clinical characteristics of coronavirus disease 2019 in China. N Eng j med. 2020;382(18):1708-20.

34. Dolan TA, Gilbert GH, Duncan RP, Foerster U. Risk indicators of edentulism, partial tooth loss and 
prosthetic status among black and white middle-aged and older adults. Comm Dentistry Oral Epidemiol. 2001;29(5):329-40.

35. Medina-Solis CE, Pérez-Núñez R, Maupome G, Avila-Burgos L, Pontigo-Loyola AP, Patiño-Marín N et al. National survey on edentulism and its geographic distribution, among Mexicans 18 years of age and older (with emphasis in WHO age groups). J Oral Rehab. 2008;35(4):237-44.

36. Mu"ller F, Manuel Naharro M, Carlsson G. What are the prevalence and incidence of tooth loss in the adult and elderly population in Europe? Clin Oral Implants Res. 2007;18(3):2-14.

37. Rao A, Sequeira P, Peter S, Rajeev A. Oral health status of the institutionalized elderly in Mangalore, India. Indian J Dent Res. 1999;10:55-61.

38. Manski R, Moeller J, Chen H, Widström E, Listl S. Disparity in dental attendance among older adult populations: a comparative analysis across selected European countries and the USA. Int Dental J. 2016;66(1):36-48.

39. Guo ZD, Wang ZY, Zhang SF, Li X, Li L, Li C et al. Aerosol and surface distribution of severe acute respiratory syndrome coronavirus 2 in hospital wards, Wuhan, China, 2020. Emerg Infect Dis. 2020;26(7):10-3201.

40. Peng X, Xu X, Li Y, Cheng L, Zhou X, Ren B. Transmission routes of $2019-\mathrm{nCoV}$ and controls in dental practice. Int J Oral Sci. 2020;12(1):1-6.

41. Izzetti R, Nisi M, Gabriele M, Graziani F. COVID19 transmission in dental practice: brief review of preventive measures in Italy. J Dent Res. 2020;99(9):1030-8.

42. Ather A, Patel B, Ruparel NB, Diogenes A, Hargreaves KM. Coronavirus disease 19 (COVID19): implications for clinical dental care. J Endod. 2020;46(5):584-95.
43. Ren YF, Rasubala L, Malmstrom H, Eliav E. Dental care and oral health under the clouds of COVID-19. JDR Clin Trans Res. 2020;5(3):202-10.

44. Harrel SK, Molinari J. Aerosols and splatter in dentistry: a brief review of the literature and infection control implications. J Am Dental Assoc. 2004;135(4):429-37.

45. Alharbi A, Alharbi S, Alqaidi S. Guidelines for dental care provision during the COVID-19 pandemic. Saudi Dent J. 2020;32(4):181-6.

46. Liu L, Wei Q, Alvarez X, Wang H, Du Y, Zhu H et al. Epithelial cells lining salivary gland ducts are early target cells of severe acute respiratory syndrome coronavirus infection in the upper respiratory tracts of rhesus macaques. $\mathrm{J}$ Virol. 2011;85(8):4025-30.

47. Indian Dental Association's Preventive Guidelines for Dental Professionals on the Coronavirus Threat. Available

at: https://www.ida.org.in/pdf/IDA_Recommendations_ for_Dental_Professionals_on_the_Coronavirus_Thre at.pdf. Accessed on 9/5/2020.

48. COVID-19 guidelines for dental colleges, dental students and dental professionals by Dental Council of India. Available at: http://dciindia.gov.in/ Admin/NewsArchives/DCI\%20Guidelines\%20on\%2 0COVID-19.pdf. Accessed on 9/5/2020.

49. Kowalski JW, Walsh JT, Petraitis V. COVID-19 Coronavirus Ultraviolet Susceptibility. Technical Report. 2020;1-5.

Cite this article as: Bhattacharjee $B$, Gupta $P$, Bhatnagar A, Singh A, Saneja R. Effect of COVID-19 in geriatric individuals and role of a prosthodontist in clinical setup in Indian populations: a literature review. Int J Sci Rep 2020;6(11):478-84. 